\title{
A Novel Approach To Improve The Performance Of Fuzzy- Logic Based Controllers For Systems With Wide Range Disturbances And Uncertain Parameters
}

\author{
A. M. Abdel-Hamid* \\ * Department of Electrical Engineering, Faculty of Engineering, El-Monoufia University, \\ Shebin El-Kom, Egypt
}

\begin{abstract}
:
Applications of fuzzy logic controllers have proved that a tuning algorithm must be added to improve its performance against the system disturbances. The tuning methods represent an additional costs and complexity for implementation. This paper, presents a novel method which implies a self-tuned controller capable of damping the system oscillations whatever the disturbance changes. Moreover, this controller is robust to a degree that permits more than $\pm 500 \%$ parameters uncertainties to be considered. The idea of this approach is to combine two control signals, one from a conventional stabilizer, e.g. lead lag compensator, and the other from a fuzzy logic controller. The stabilizer is designed based on modal techniques for the worst case of oscillations and is independent on the system disturbance. On the other side, the ranges of membership functions required for the design of fuzzy logic controller are selected based on the worst experience of the input/output behavior. The final controller is tested for different disturbances and system parameters and the results show a satisfactory performance and robustness.
\end{abstract}

\section{Introduction}

Referring to Fig.(1), one can understand Fuzzy Logic (FL) as a logical system, which is an extension of multivalued logic. It is almost synonymous with the theory of fuzzy sets, a theory which relates to classes of objects with entrap boundaries in which membership is a matter of degree [1]. The basic concept underlying FL is that of a linguistic variable, that is, a variable whose values are words rather than numbers. In effect, much of FL may be viewed as a methodology for computing with words rather than numbers. Although words may be less precise than numbers, their use is closer to human intuition. Furthermore, computing with words exploits the tolerance for imprecision and thereby lowers the cost of solution. Another basic concept in FL, which plays a central role in most of its applications, is that of a fuzzy if-then rule or, simply, fuzzy rule.

Manuscript received from Dr; A. M. Abdel-Hamid on : 19/6/1999

Accepted on: 31/7/1999

Engineering Research Bulletin, Vol 22, No 3, 1999

Minufiya University, Faculty of Engineering, Shebin El-Kom , Egypt, ISSN $\quad 1110-1180$ 

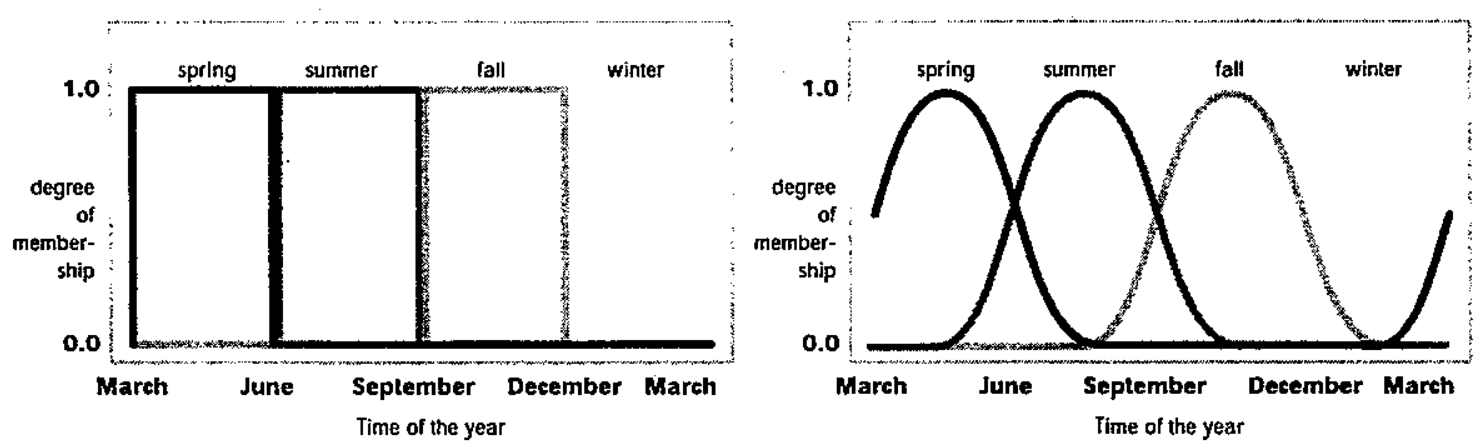

Fig.(1) The answer of the session question expressed in two-and multi-valued membership

The past few years have witnessed a rapid growth in the number and variety of applications of fuzzy logic. The applications range from consumer products such as cameras, camcorders, washing machines, and microwave ovens to industrial process control like drives, power systems medical instrumentation, and decision-support systems. Applications of fuzzy logic controllers have proved that a tuning algorithm must be added to improve its performance against the system disturbances $[2,3,4,5]$. The tuning methods are almost based on applying phase plane to calculate factors used as references for more additional membership functions. This complicates the implementation of these methods with microprocessors and adds more costs for the overall system beside increasing the rules if the system uncertainties are also to be considered.

This paper, presents a novel method which implies a self-tuned controller capable to damp the system oscillations whatever the disturbance changes. Moreover, this controller is robust to a degree that permits more than $\pm 500 \%$ parameters uncertainties to be considered. The idea of this approach is to combine two control signals, one from any conventional controller such as PI controller, stabilizer, or a lead lag compensator and the other from a fuzzy logic controller. The conventional controller is designed based on modal techniques for the worst case of oscillations. Since conventional controllers are essentially based on equivalence linearized dynamics about an operating point, they will not depend on the system disturbances. This guarantee system performance which is independent on the amount of disturbance. On the other side, the ranges of membership functions of the fuzzy logic controller is selected based on the worst experience of the input/output behavior. This, also, assures the controller robustness against the variations of system parameters due to any kind of modeling imprecision and/or uncertainty. The final controller is applied on a power system composed of a single machine connected to an infinite bus via a transmission line $[6,7,8,9]$.

\section{The Proposed System And Controller}

Figure (2) shows a schematic and block diagram of the system under study. Part (a) of this figure shows a power system which is composed of a single machine connected to an infinite bus via a transmission line. Part (b), shows the well known 'deMello and Concordia [6] first linearized model of the single machine system. The details of this model can be founded by reference to their paper[6] and the per unit nomenclature used will be given in the appendix. This model is extensively used for the design of power System Stabilizers (PSS) and will also be used in this paper as an application system for the proposed new control approach. It is clear from this figure that a fuzzy logic controller will be added in parallel with the PSS , not only as an auxiliary controller to enhance the damping of power system oscillations, but also as a 
guarantee of controller robustness against disturbances change and parameters variations. Both the PSS and the fuzzy logic controller are fed from the speed deviations and the resulting signals will feed the system as shown in the mentioned figure.

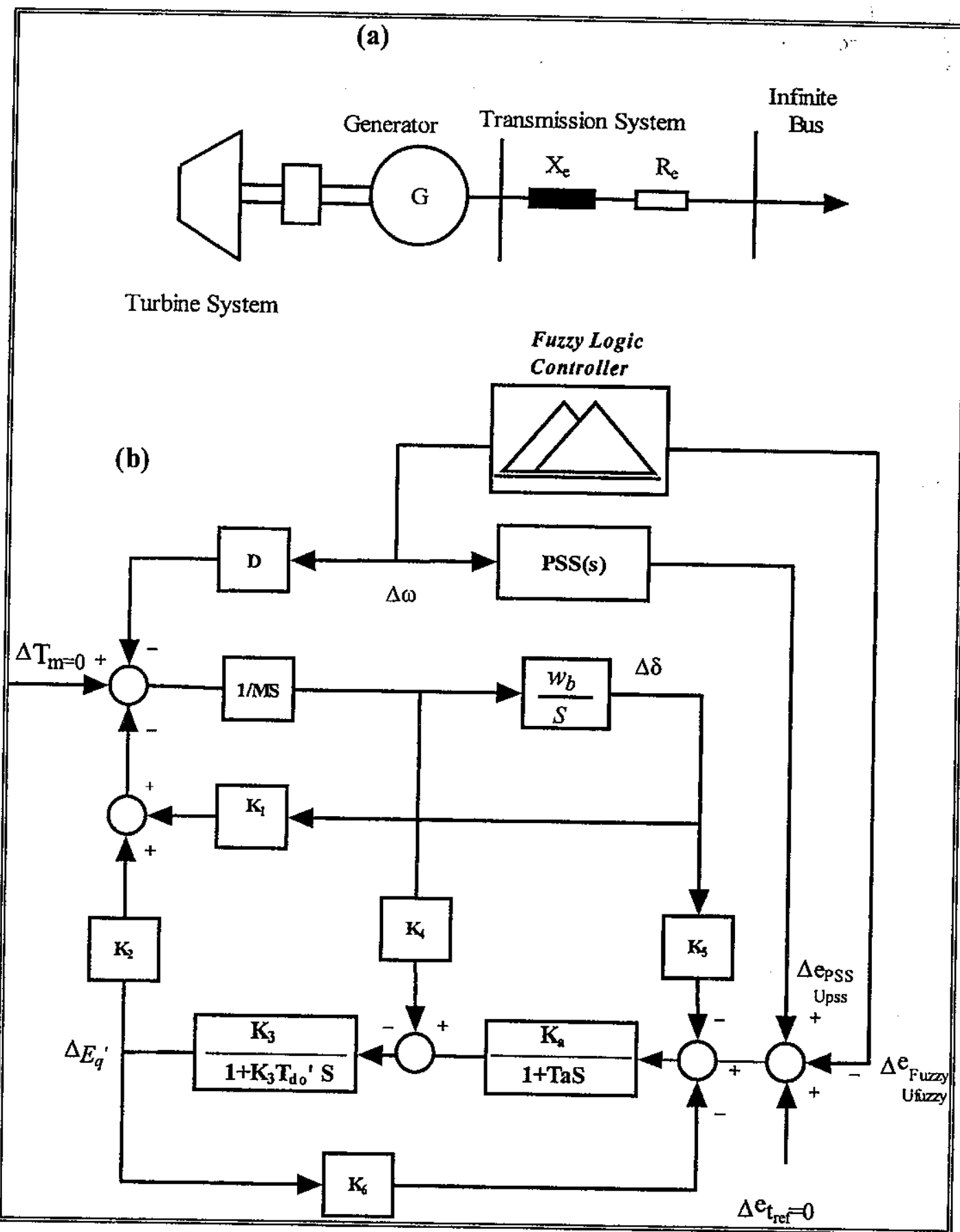

Fig.(2) The Power System Model: (a) Diagram of a single machine to infinite bus system (b) Linearized model of the system shown in (a) (The PSS and the fuzzy logic controllers also appear in part ' $b$ ') 


\subsection{The PSS Response:}

Power system stabilizers are widely used [6-10] to improve the system steady state stability, i.e. the performance of synchronous generator under disturbance conditions. PSS is considered as a feedback controller connected to a power generating unit. The purpose of stabilizing signal from PSS is to hinder poor-damped machine speed electro-mechanical oscillation. These oscillations are essentially due to the pair of complex poles with positive or very small negative real parts in a linearized model. For a steam unit having these a nominal operating conditions:

$P=1.0$ p.u. $\quad Q=0.2$ p.u. $\quad X_{e}=0.4$ p.u., while $R_{\mathrm{e}}$ is neglected

and for the block diagram of Fig. (2-b) the following data are valid:

$M=10$ s. $\quad D=0.0$ p.u. $\quad x_{d}=1.6$ p.u. $\quad x_{q}=1.55$ p.u. $\quad x_{d}{ }^{\prime}=0.32$ p.u.

$T_{d o}{ }^{\prime}=6.0 \mathrm{~s} . \quad k_{a}=25.0 \quad T_{a}=0.05 \mathrm{~s}$

The overall power system transfer function PSTF between $\Delta w$ and Upss(s) is:

$$
-11.121
$$

$$
\begin{aligned}
G(s)=P S T F & :=- \\
s^{2} & +20.463 s^{3}+80.95 s^{2}+841.166 s+1771.779
\end{aligned}
$$

factoring this TF, the following "Maple" program shows that the unstable electro-mechanical modes are: $(s-.07899529449+6.412145157 l) .(s-.07899529449-6.412145157 l)$

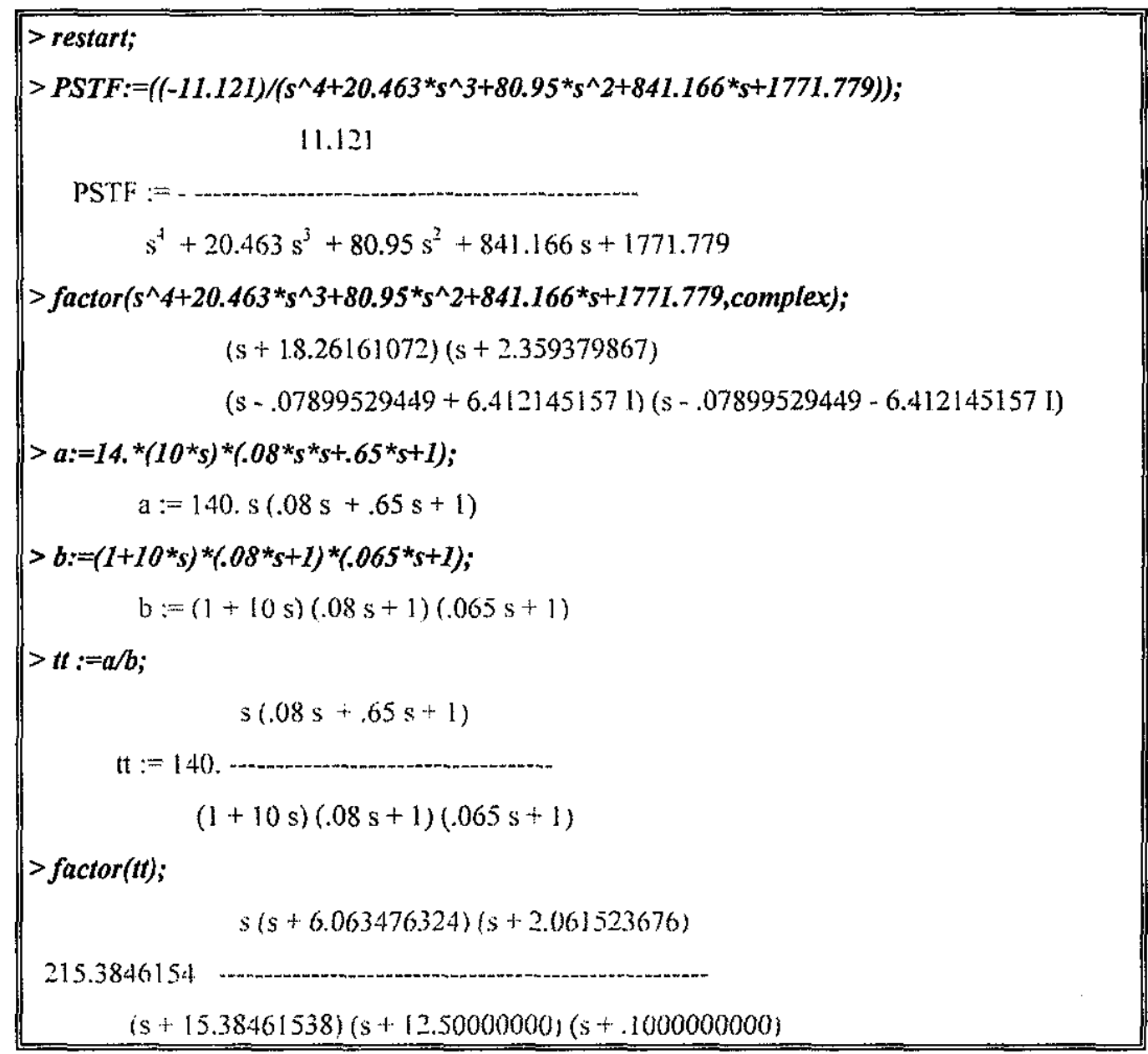




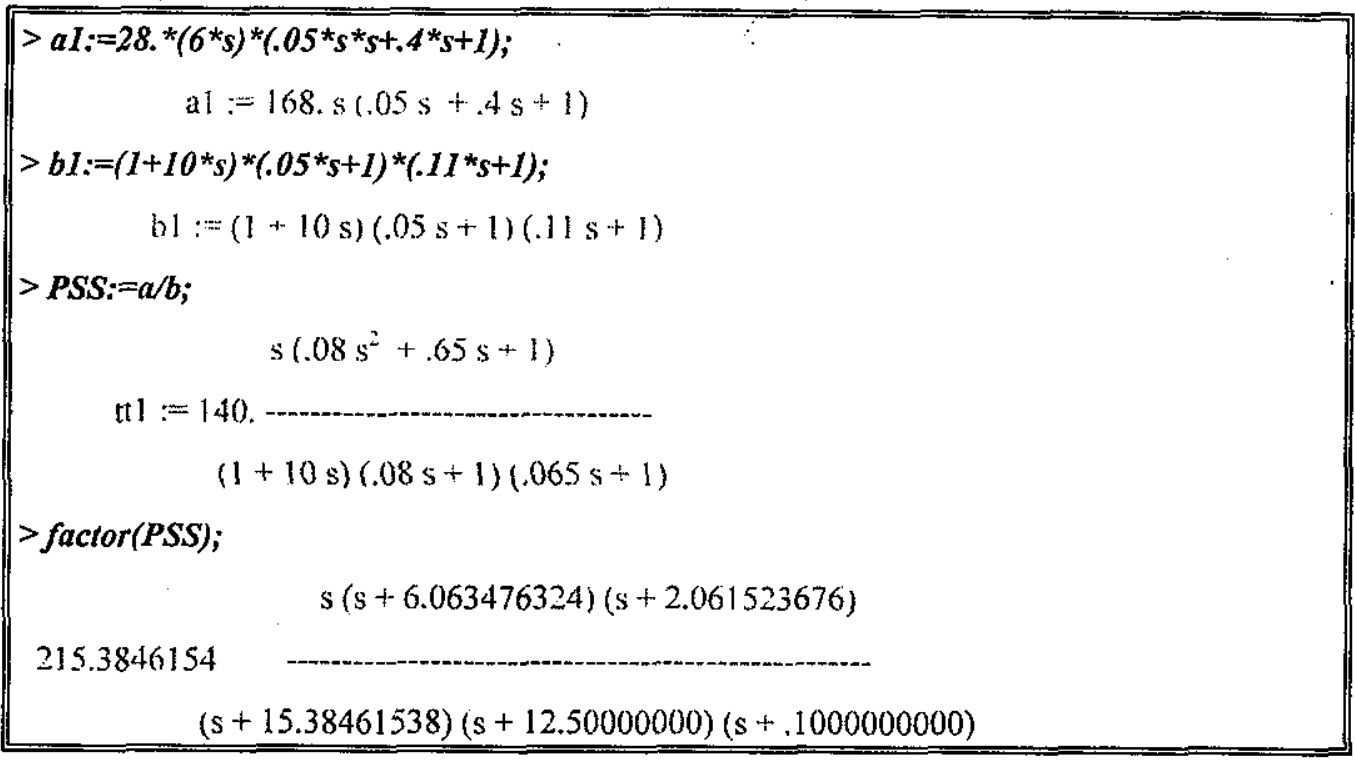

In order to inhibit these two poor-damped electro-mechanical oscillation a PSS having the TF as follows:

$$
P S S(s)=K_{s} \frac{T_{w} s}{1+T_{w} s} \frac{1+T_{1} s}{1+T_{2} s} \frac{1+T_{3} s}{1+T_{4} s}
$$

is assumed. According to the modal algorithm given by the author in [11], the above unstable mode is moved to a more stable location with " $-6.5 \pm 6.5 I$ " and the resulting PSS variables are found through solving the resulting nonlinear equations to be:

\section{$T_{w}=10.0, \quad K_{s}=14, \quad T_{1}=0.485, \quad T_{2}=0.08, \quad T_{3}=0.165, \quad T_{f}=0.065$}

applying these results on the PSS(s) equation, the above "Maple" Program give a factored form of PSS equation in the form:

$$
s(s+6.063476324)(s+2.061523676)
$$

$P S S(s)=215.3846154$

(3)

$(s+15.38461 .538)(s+12.50000000)(s+.1000000000)$

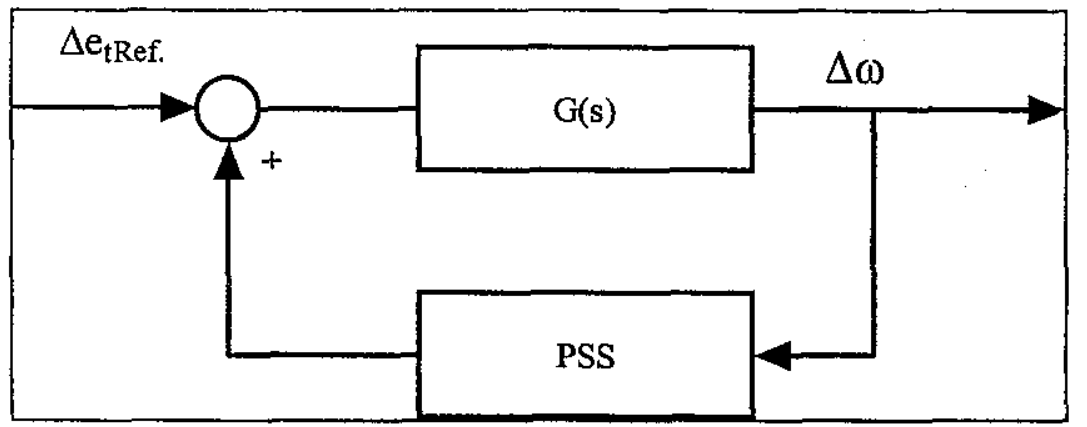

Fig.(3) The PSS and the Power System Model:

the above power system transfer $G(s)$, eqn(1), and the PSS(s), eqn.(3) are shown in Fig.(3). The above system is simulated and the results for the previously given system data and the nominal operating conditions are shown in Fig.(4) and Fig(5). 


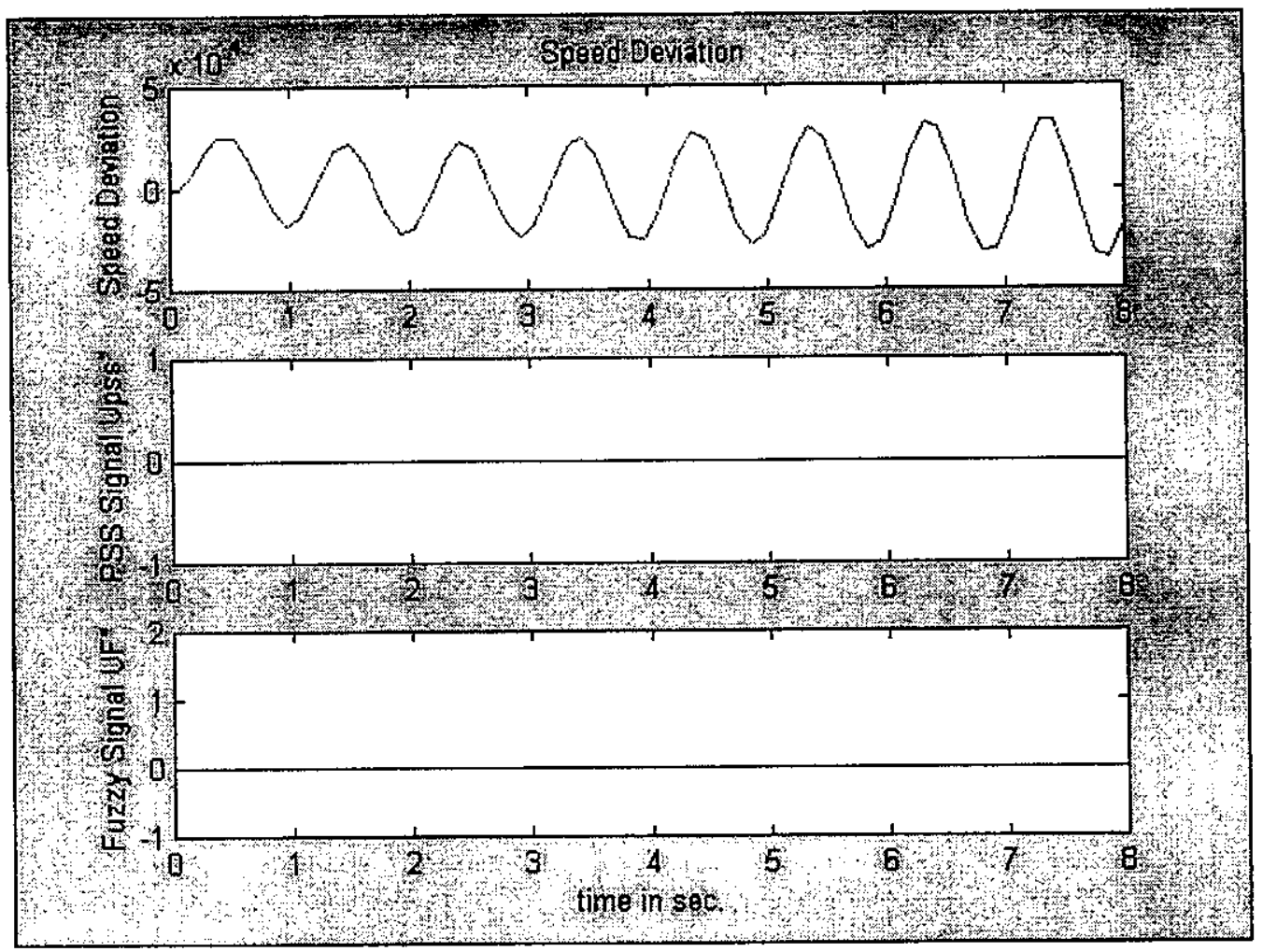

Fig.(4) The Power System response to a $0.015 \%$ step change in the terminal voltage (Open Loop and nominal data)

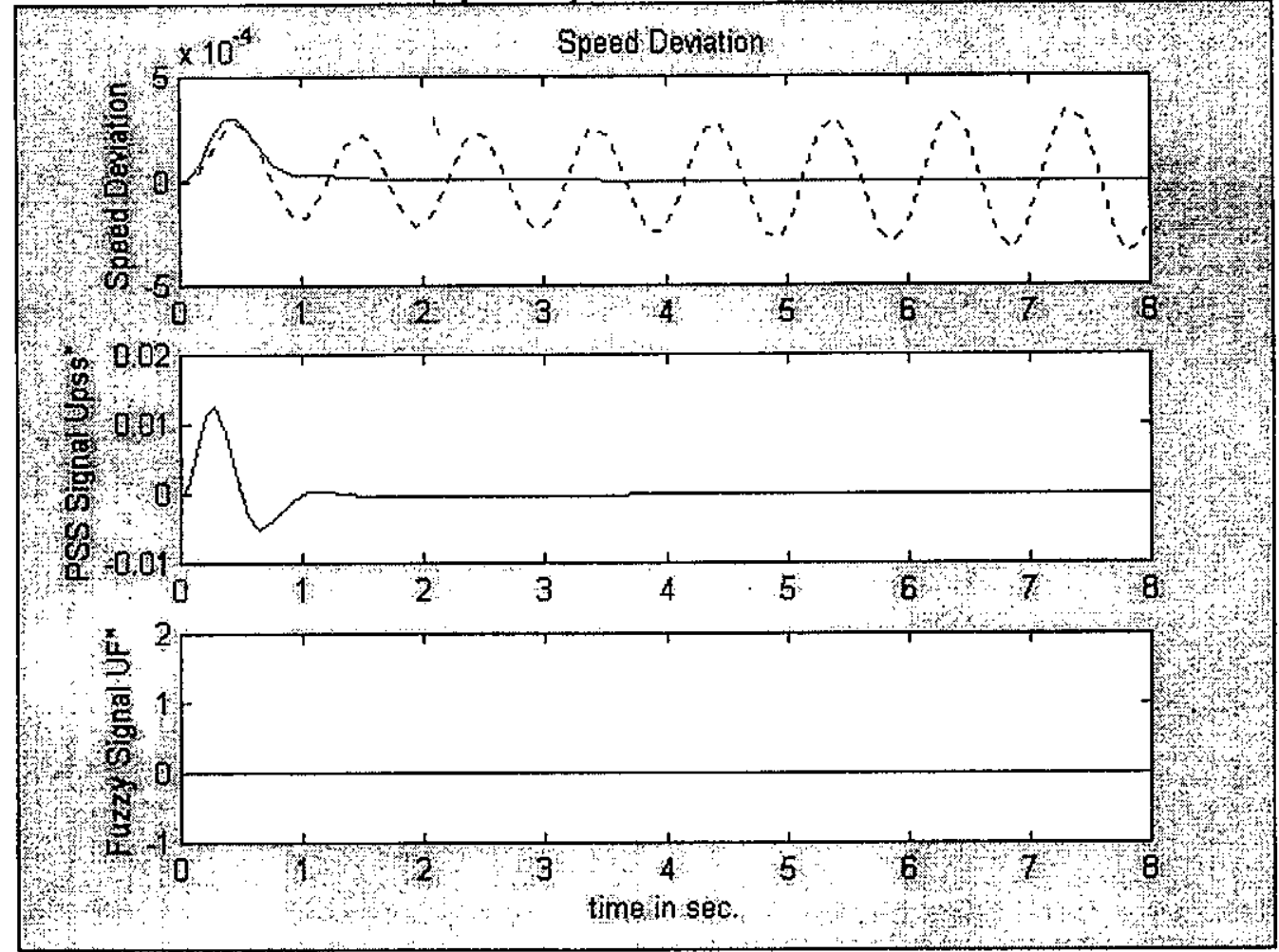

Fig.(5) The Power System response to a $0.015 \%$ step change in the terminal voltage (Closed Loop and nominal data, PSS only.) 
However, the above results are very acceptable if the operating conditions and the system data remain unchanged. Unfortunately, it is a well known feature of power systems that the operating conditions are always varying. Also the parameters of the power system are very sensible to any change in the system components. For example, an extensive calculations of the constants of part (b) of Fig. (2) has been performed to show the change in the significant $\mathbf{K}^{\prime \mathbf{s}}$, i.e. $\mathbf{K}_{1} \sim \mathbf{K}_{6}$. The following table give a summery of the change of these constants if the line reactance is changed.

Table (1) Variations in model parameters with line reactance

\begin{tabular}{|c|c|c|c|c|}
\hline & Case 1 & Case 2 & Case 3 & Case 4 \\
\hline & $\begin{array}{l}\mathrm{P}=0.736 \text { p.u. } \\
\mathrm{Q}=0.128 \text { p.u. } \\
\mathrm{X}_{1}=0.2 \text { p.u. } \\
\mathrm{V}_{\infty}=0.92 \text { p.u. }\end{array}$ & $\begin{array}{l}\mathrm{P}=0.736 \text { p.u. } \\
\mathrm{Q}=0.256 \text { p.u. } \\
\mathrm{X}_{1}=0.4 \text { p.u. } \\
\mathrm{V}_{\infty}=0.92 \text { p.u. }\end{array}$ & $\begin{array}{l}\mathrm{P}=0.736 \text { p.u. } \\
\mathrm{Q}=0.384 \text { p.u. } \\
\mathrm{X}_{\mathrm{I}}=0.6 \text { p.u. } \\
\mathrm{V}_{\infty}=0.92 \text { p.u. }\end{array}$ & $\begin{array}{l}\mathrm{P}=0.736 \text { p.u. } \\
\mathrm{Q}=0.512 \text { p.u. } \\
\mathrm{X}_{1}=0.8 \text { p.u. } \\
V_{\infty}=0.92 \text { p.u. }\end{array}$ \\
\hline $\boldsymbol{K}_{I}$ & 2.2851 & 1.4803 & 1.0951 & 0.8692 \\
\hline $\bar{K}$, & 1.7229 & 1.2129 & 0.9503 & 0.7865 \\
\hline$K_{3}$ & 0.3137 & 0.3881 & 0.4479 & 0.4971 \\
\hline$K_{1}$ & 0.5026 & 0.4819 & 0.4583 & 0.4342 \\
\hline$K_{5}$ & -0.0837 & -0.0997 & -0.1019 & -0.09877 \\
\hline$\overline{K_{6}}$ & 0.4304 & 0.5947 & 0.9620 & 0.7577 \\
\hline
\end{tabular}

from this table it is clear how the system parameters can be completely differ from one operating point to another one. It is important to refer that the $S$ - factors of the previously given $G(s)$ in equation (1) are functions of these $\mathrm{K}^{\prime s}$. Hence, another response is expected if these parameters

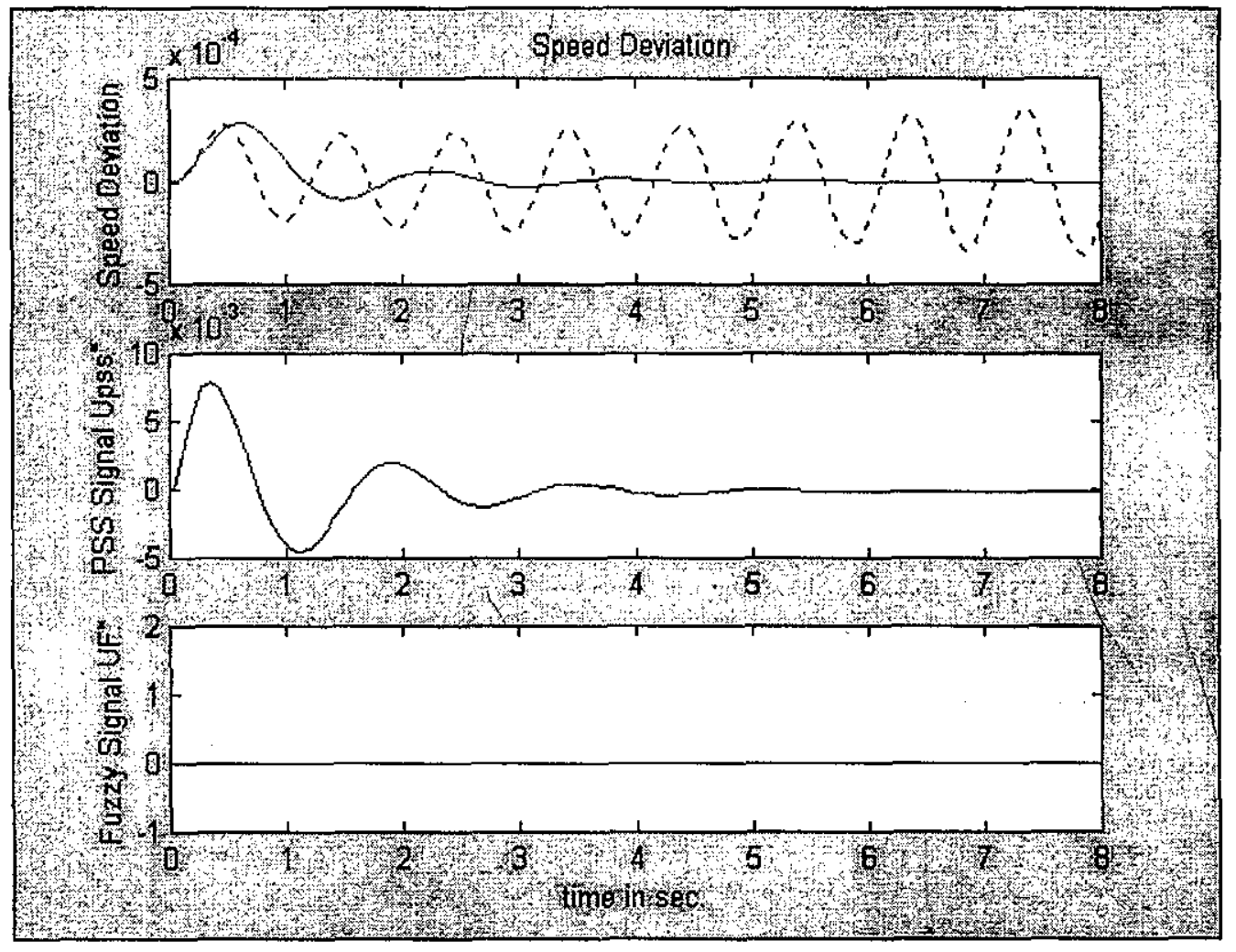

Fig.(6) The Power System response to a $0.015 \%$ step change in the terminal voltage

(Closed loop and a $50 \%$ increase in the $G(s)$ parameter $K_{d}$, PSS only) 


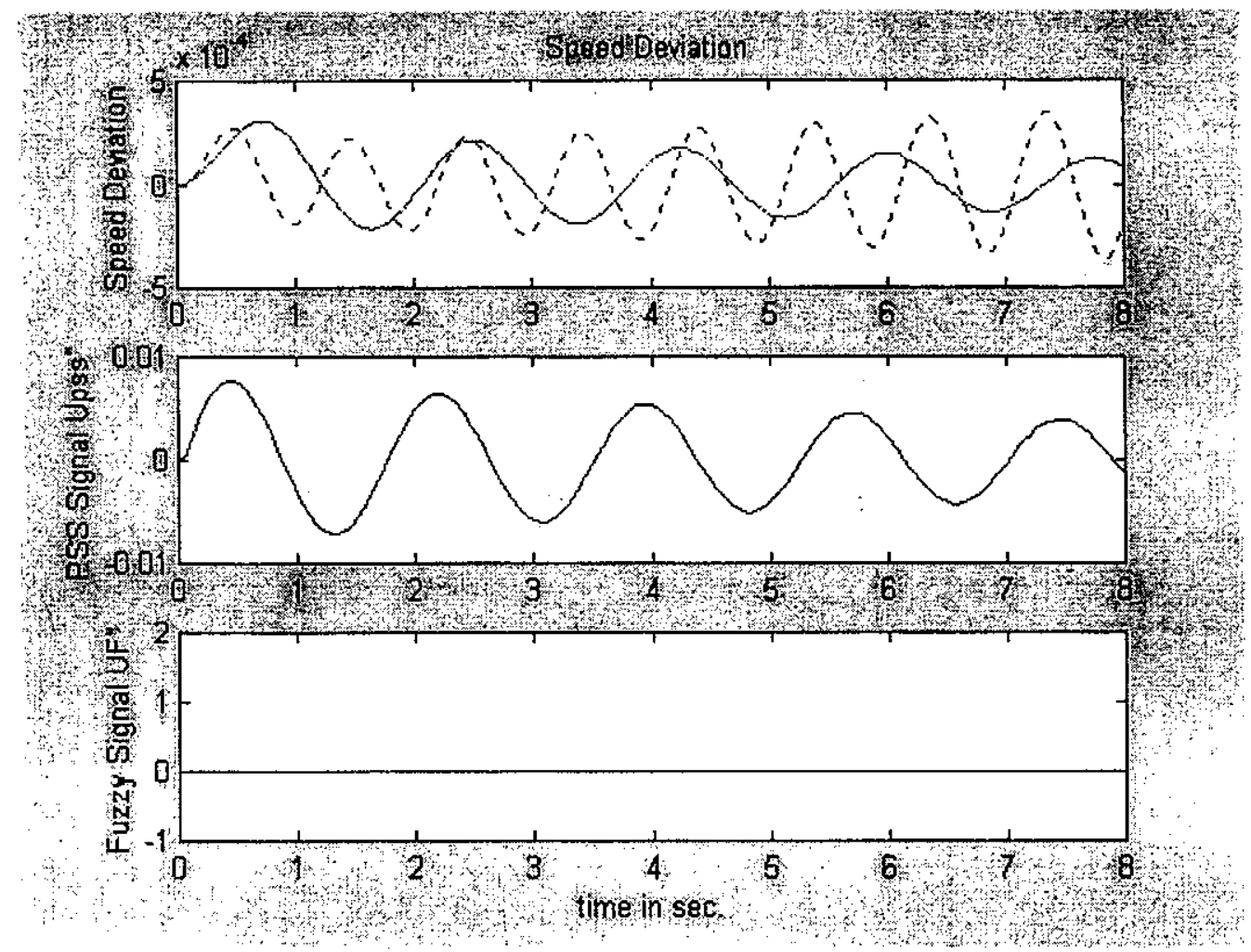

Fig.(7) The Power System response to a $0.01 \%$ step change in the terminal voltage

(Closed loop and a $500 \%$ increase in the $G(s)$ parameter $K_{d}$ ) (PSS only)

are changed. Figure (6) shows the system response if a light change in these parameters is assumed in the G(s) function. It is clear that the PSS alone can't hinder these changes especially if the change of these parameters is high enough to give the results of Fig.(7). In the above figures only one parameter is assumed to change. This parameter is the factor of " $s^{3}$ " in Eqn.(1) and will be referred as " $K_{d} "\left(K_{d}\right.$ nominal $\left.=20.463\right)$. However, it is known that all the factors of the denominator of this equation are functions of the previously mentioned $\mathbf{K}^{\prime 3}$ (i.e. $\mathbf{K}_{\mathbf{1}} \sim \mathbf{K}_{6}$ ) [6].

\subsection{The Proposed Fuzzy Logic Controller:}

Fuzzy logic controllers (FLC) represent one of the recent control alternatives which are widely used in many applications during this recent decade. The attraction of Fuzzy Logic (FL), in general, lays in the fact that it can yield a controller which acts in a manner similar to human language. The theory of FL and FLC can be found anywhere in the literature. However reference [13] can be very helpful to get started very simply in this field. It is also important to be aware of the physical system to be controlled using FLC. This will simplify the steps leading to an efficient and reasonable FLC. In summary, the so called Mamdani's fuzzy inference method $[12,13]$ is the most commonly seen fuzzy methodology. Mamdani's method was among the first control systems built using fuzzy set theory. This methodology process constitutes these steps:

Step 1. Fuzzify Inputs: This means how to select the inputs for FLC and determine the degree to which they belong to each of the appropriate fuzzy sets via membership functions.

Step 2. Apply Fuzzy Operator: Once the inputs have been fuzzified, One knows the degree to which each part of the antecedent has been satisfied for each rule. If the antecedent of a given 
rule has more than one part, the fuzzy operator is applied to obtain one number that represents the result of the antecedent for that rule. This number will then be applied to the output function. Step 3. Apply Implication Method: Simply the usage of "OR" or "AND".

Step 4. Aggregate All Outputs: This is the process by which the fuzzy sets that represent the outputs of each rule are combined into a single fuzzy set.

Step 5. Defuzzify: Since the aggregate of a fuzzy set encompasses a range of output values, and so must be defuzzified in order to resolve a single output value from the set.

The purpose of this paper, principally, is how to solve the problem of generating appropriate membership functions whatever the grade of disturbance may be. In the early work of Malik and Hassan $[2,3]$, a tuning technique is proposed to solve this problem in the work of Hiyama, $[4,5]$. Unfortunately, beside the complications of this approach due to its extra rule which is determined based on phase plane, the added parameter " $R$ " (refer to their papers) is a function of a previous disturbance which is basically unpredictable and only (refer to the results in $[2,3]$ ) theoretical results can be satisfactory. Therefor, this paper presents a new approach to solve this problem. The idea of this approach is to combine two control signals, one from a conventional stabilizer, e.g. lead lag compensator, and the other from a fuzzy logic controller. The stabilizer is designed based on modal techniques for the worst case of oscillations and is independent on the system disturbance. On the other side, the ranges of membership functions required for the design of fuzzy logic controller are selected based on the worst experience of the input/output behavior. The Matlab Fuzzy Logic Controller toolbox is used to implement this approach and a Simulink block diagram for the previously mentioned power system of Fig.(2) is performed and shown in Figure (8). This figure also indicates the control strategy used in this paper.

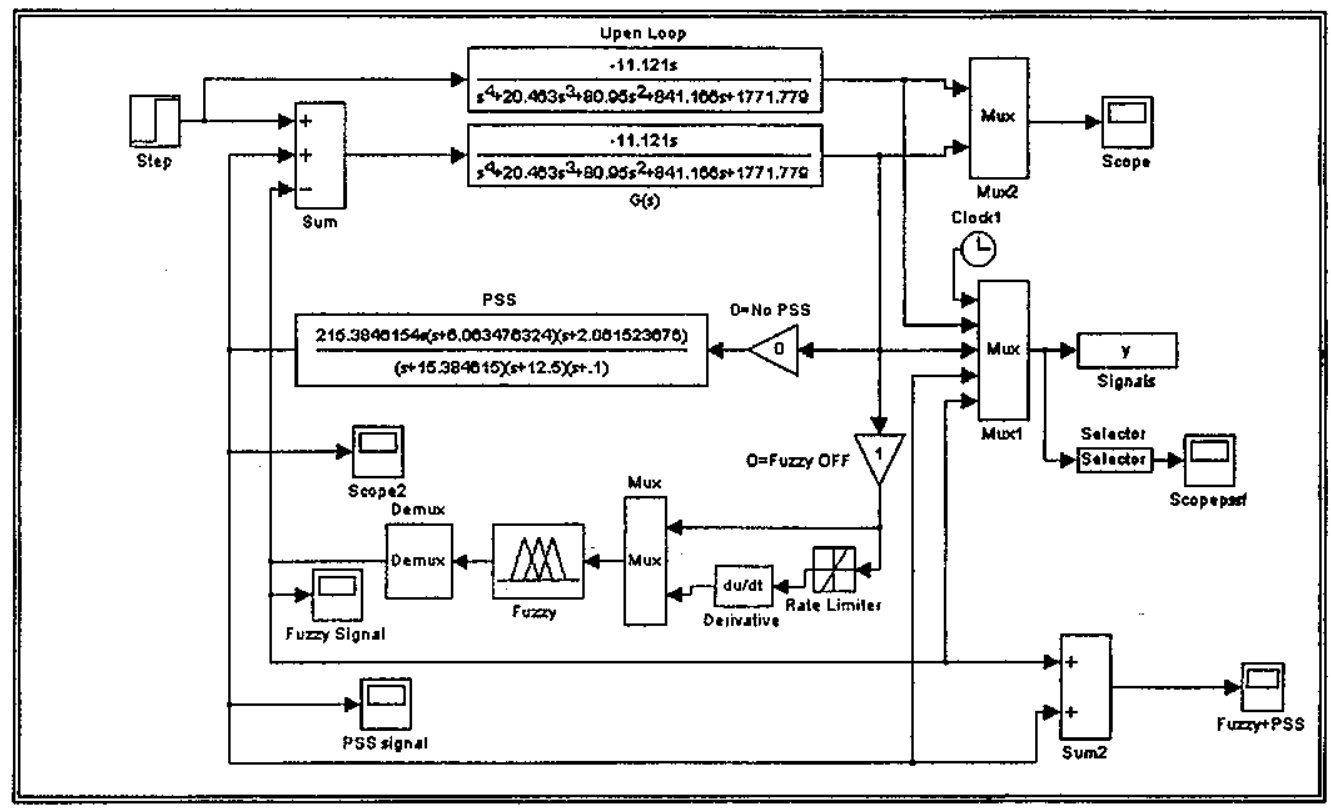

Fig.(8) A Simulink model of the proposed Power System and Controller

This model is previously used to simulate the power system with the application of PSS, and the results showed unsatisfactory damping if the system parameters are changed. In this section, the FLC is put to work firstly with the nominal parameters and operating conditions and the system response is shown in Figs. $(9,10,11)$. It is clear that at this disturbance the FLC is more efficient than PSS. The same result is shown in the three figures to focus that only light oscillations (scale of Figs. $(10,11)$ is $10^{-6}$ rather $10^{-4}$ as in Fig. (8)). However, in Fig.(11), the execution time is extended to 30 seconds to show the speed will be settled after a long time. It is clear that the FLC is very efficient and leads to very little sways which can be neglected. At this point, it is 
convenient to refer that the previously mentioned Fuzzy Logic Toolbox of Matlab which is used to implement the proposed controller have the advantage of enabling the user to show the controller structure, the rules, a view of the fuzzy process (called rule viewer) and a surface viewer to check the control strategy as a whole in an online manner with every design change: This is clear if one note the figures (12-15) for the proposed controller.

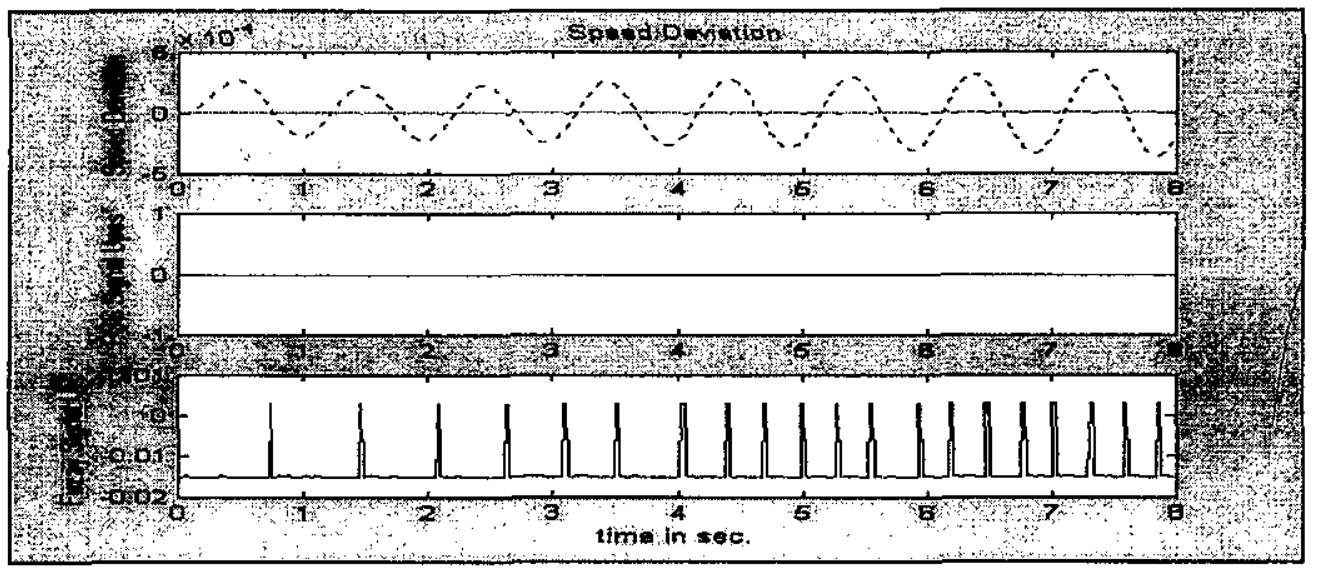

Fig.(9) The Power System response to a $0.015 \%$ step change in the terminal voltage

(Closed Loop and nominal data, FLC only)

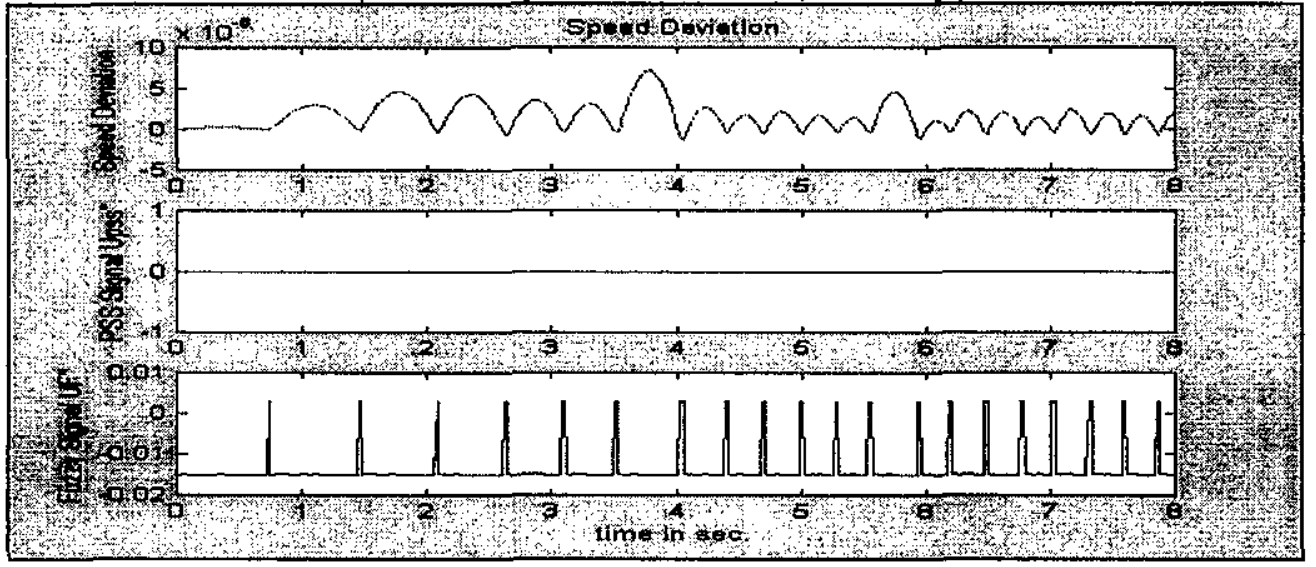

Fig.(10) The same results of Fig.(9) without the dashed curve of the uncontrolled speed (note the scale of speed to show the only light sways resulted if FLC is applied)

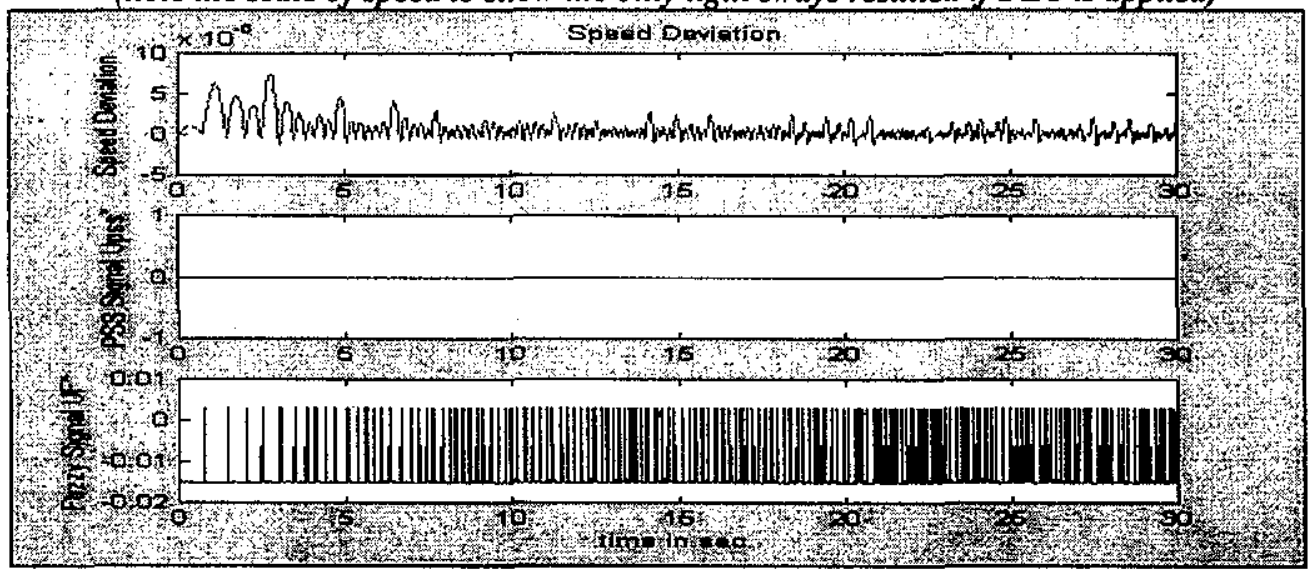

Fig.(11) The same results of Fig.(9) without the dashed curve of the uncontrolled speed (note that the simulation time is enlarged to 30 seconds) 


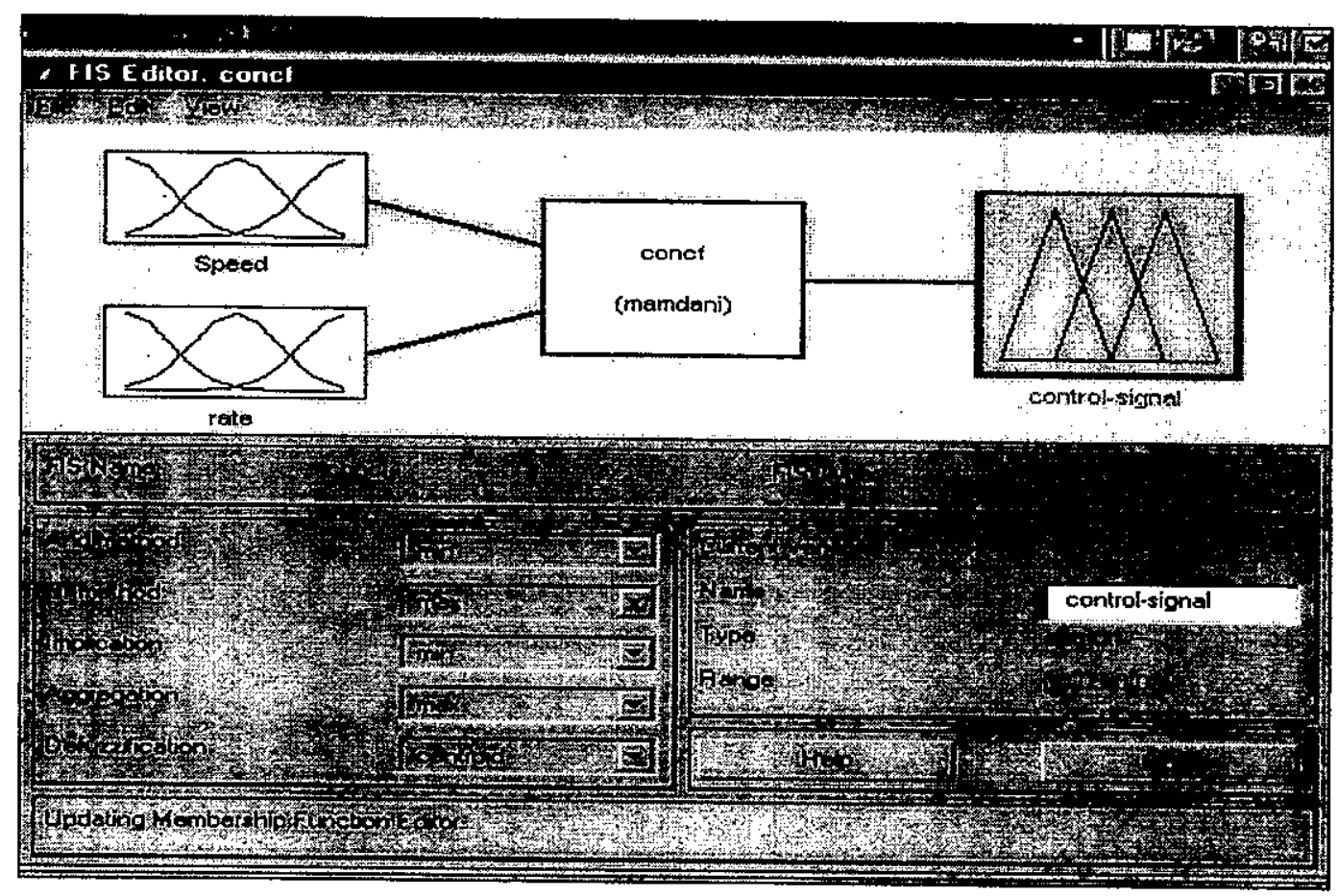

Fig.(12) The FLC siructure (Two inputs, namely, the speed and its rate of change and one output, i.e. the required control signal)

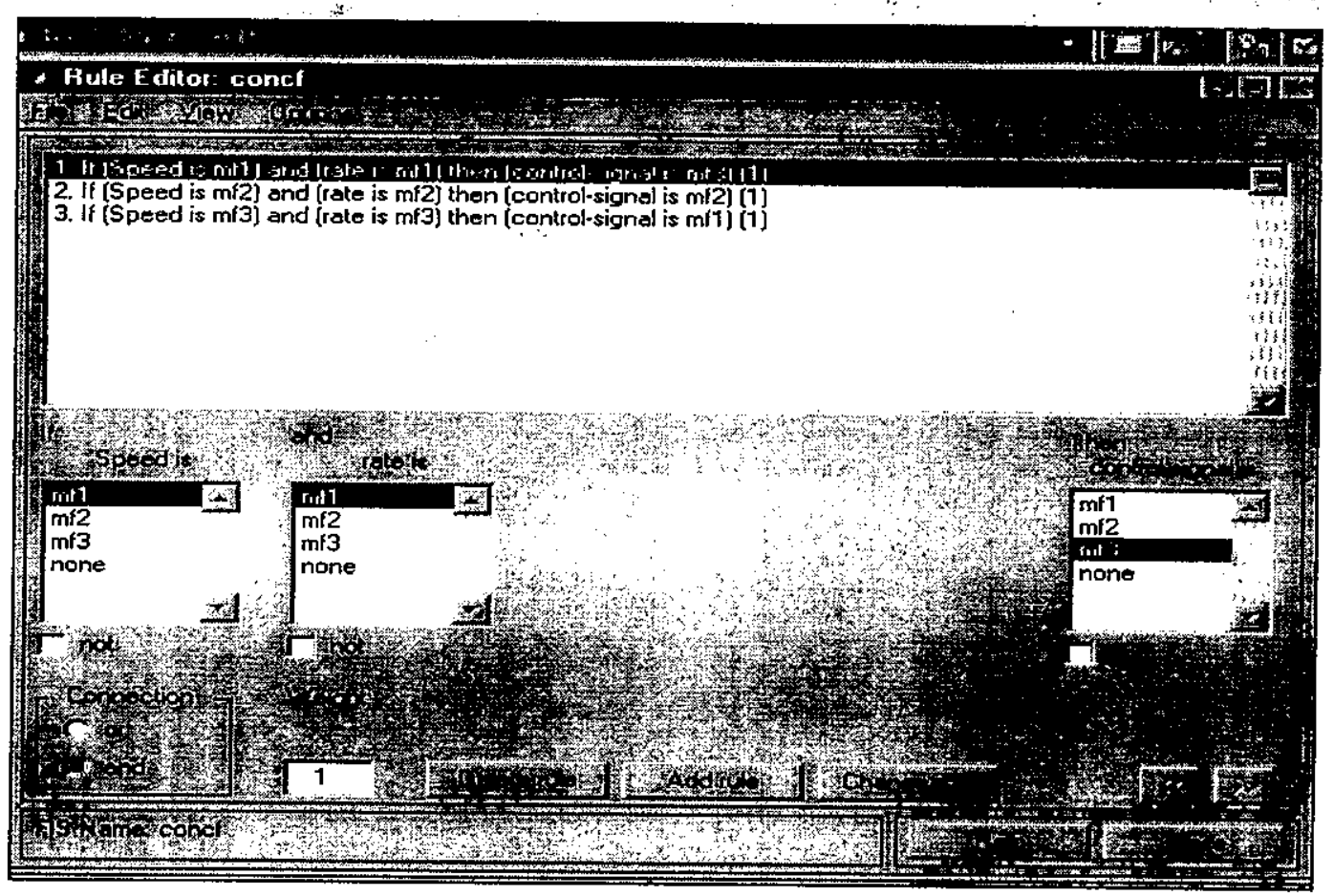

Fig.(13) The rules of the proposed FLC 


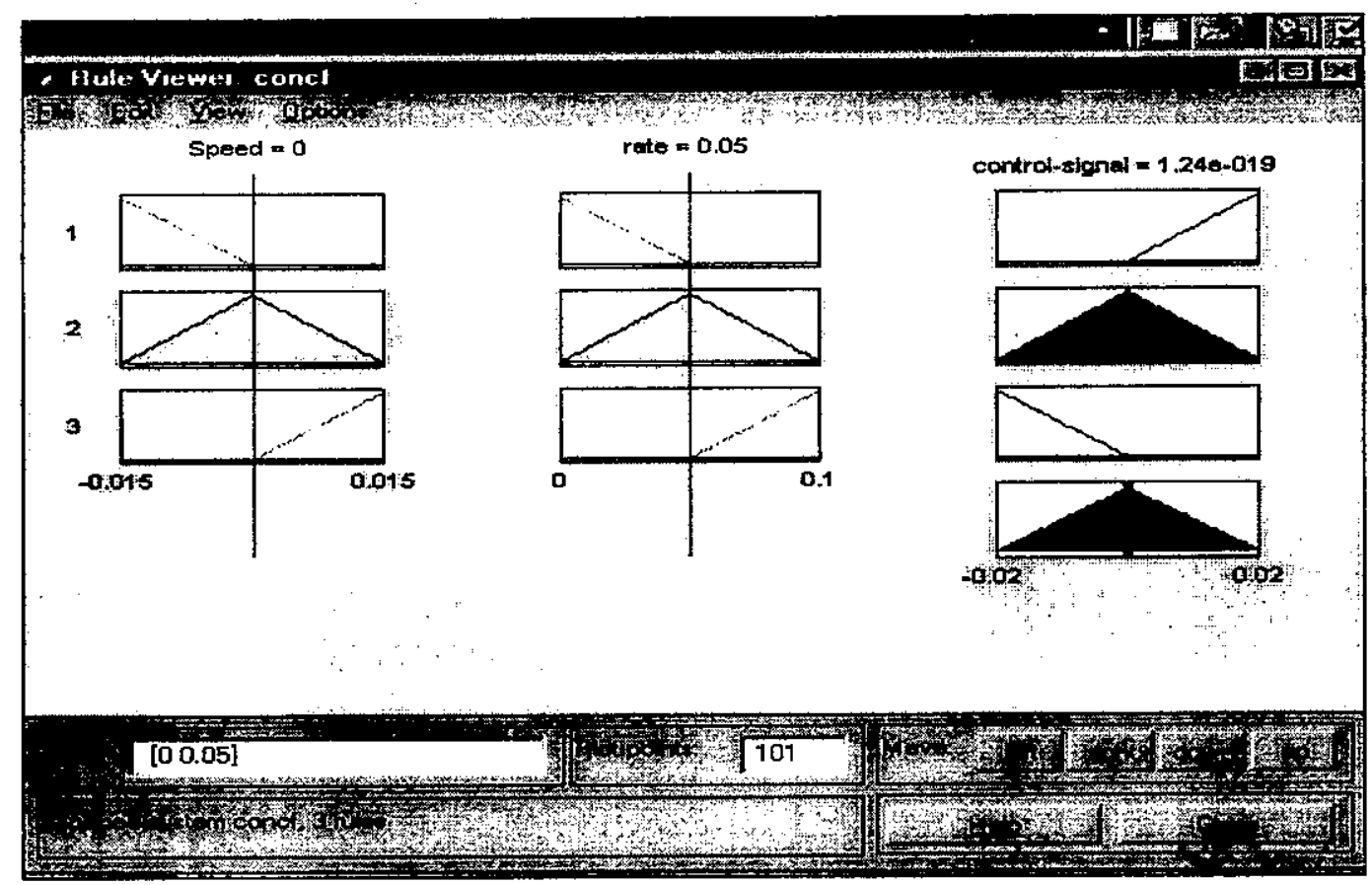

Fig.(14) The results of the rule viewer at any random conditions

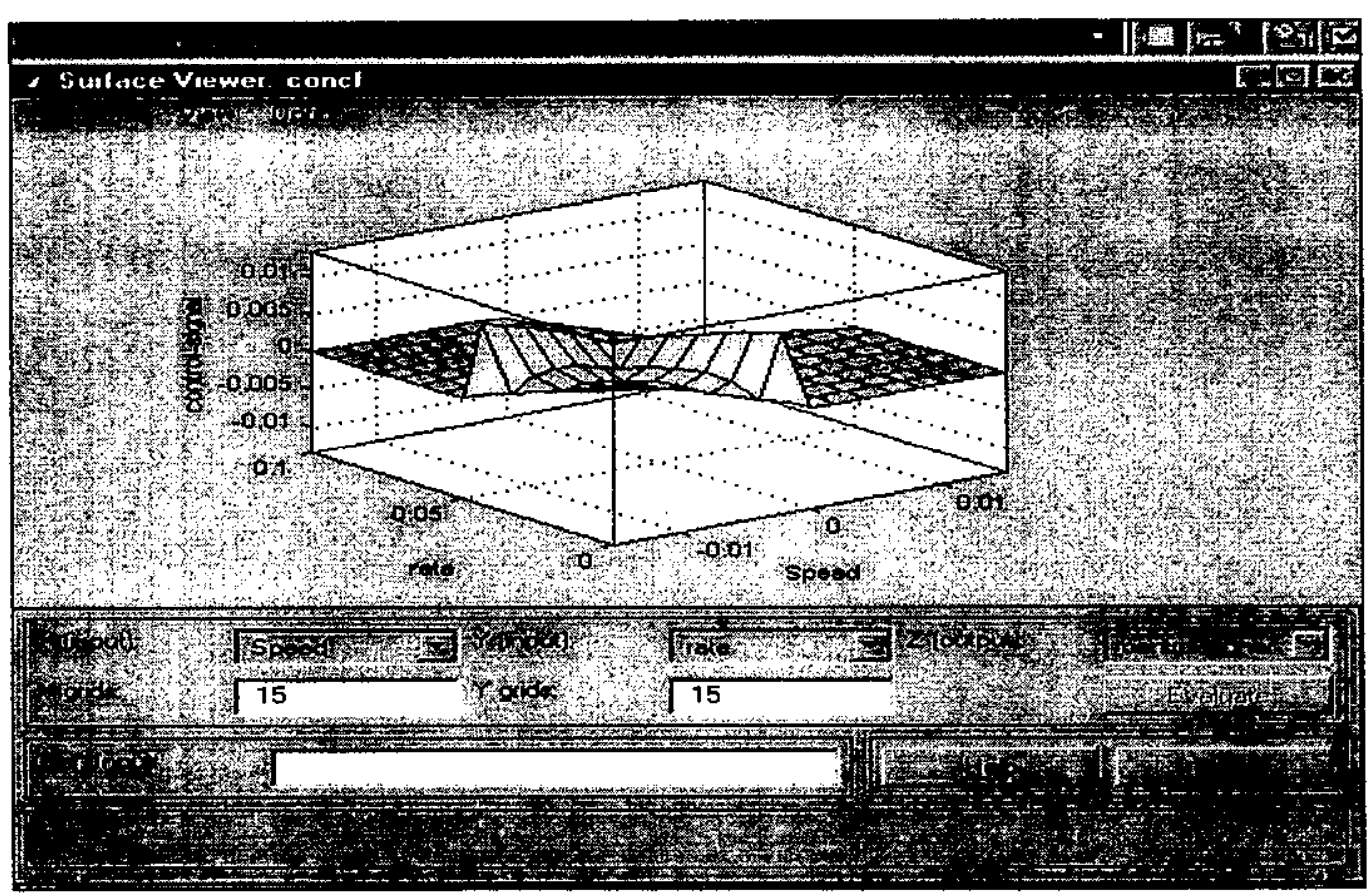

Fig.(15) The 3-D surface viewer indicates all the possible controller decisions 


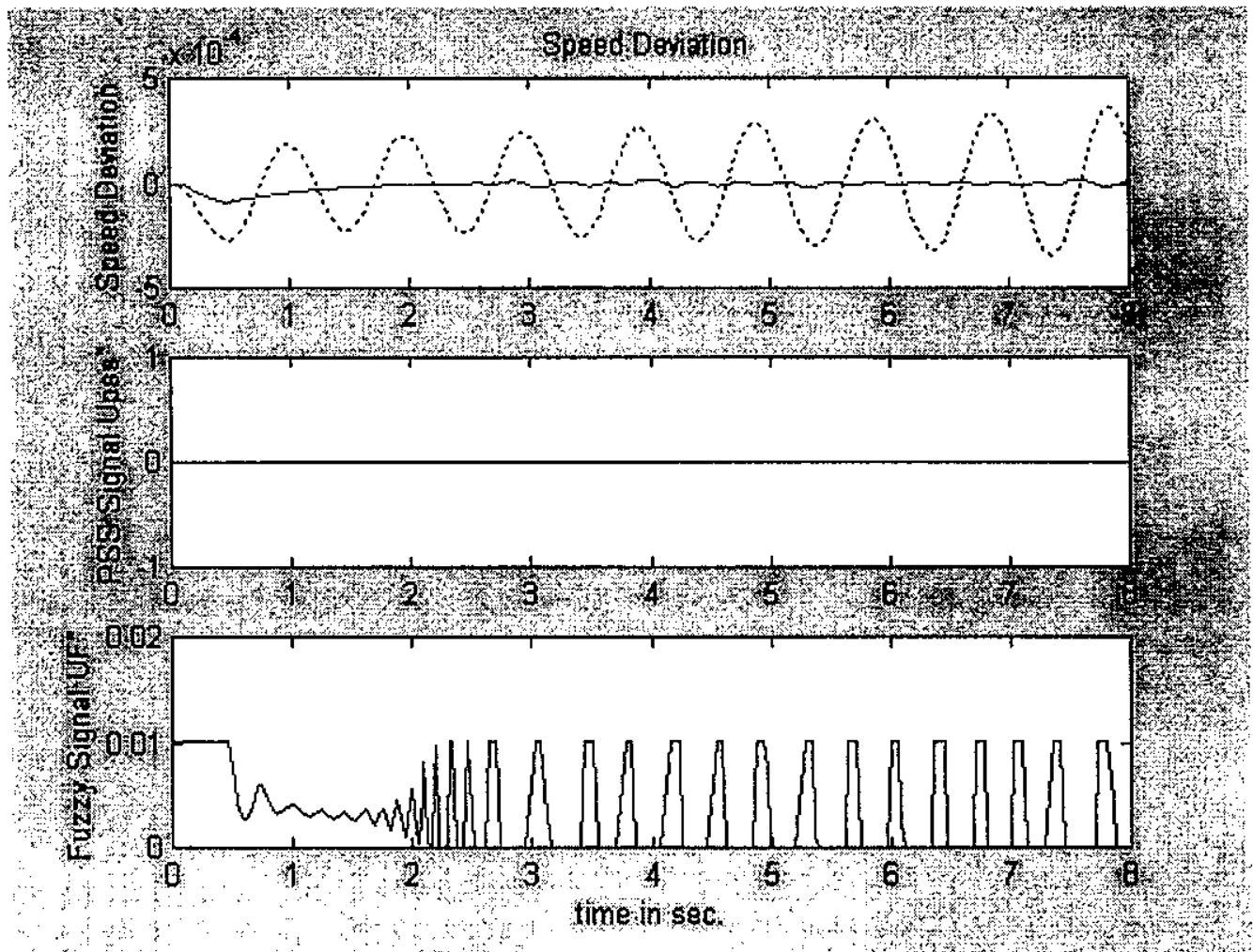

Fig.(16) The Power System response to a $0.01 \%$ step change in the terminal voltage (Closed Loop and nominal data, FLC only)

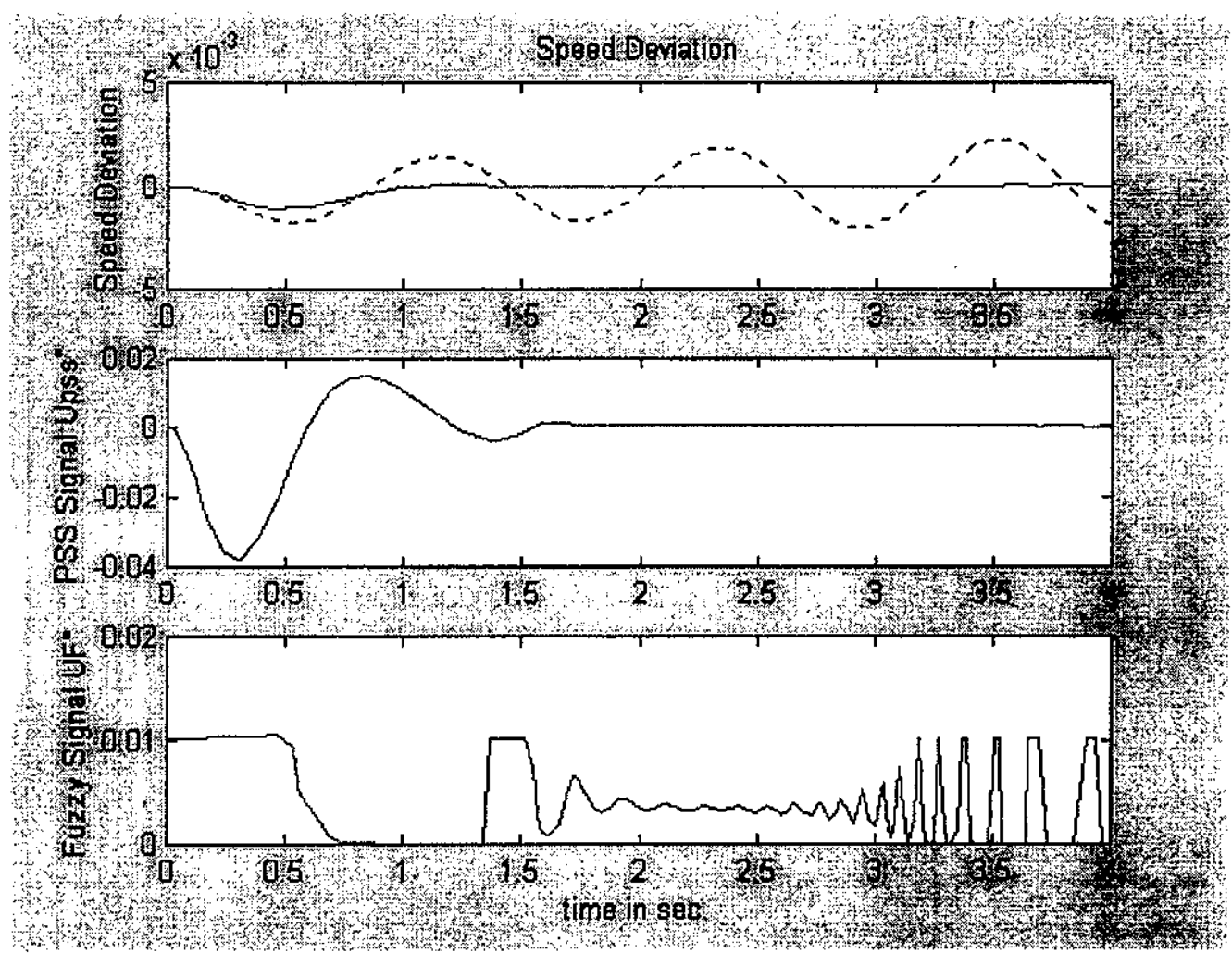

Fig.(17) The Power System response to a $0.1 \%$ step change in the terminal voltage (Closed loop and a $500 \%$ increase in the $G(s)$ parameter $\left.K_{d}\right)(P S S+F L C)$ 
The membership functions selected for a certain disturbance have proven to produce a robust FL controller (Refer again to Figs.(9-11)). However, if a light change in the disturbance takes place these membership functions have to be tuned to keep such controller robustness (Fig.(16) shows speed oscillations for only 0.005 change in the system disturbance.). As the purpose of this paper is to avoid extra rules based on nonlinear calculations in order to reconstruct (tune) the membership functions, a combination between the above designed PSS and FLC have shown to be sufficient to get a robust controller against a wide range of disturbances and for parameters change which may exceed $500 \%$ of those nominal values. Figure (17) shows the results of the proposed controller if a disturbance of $10 \%$ (instead of $1 \%$ ) and a $500 \%$ change in one of the dominant parameters. In a relatively short time $(1.5 \mathrm{Sec}$.) the speed deviations will be damped.

\section{Conclusions}

This paper has proposed a novel approach to avoid the complexity which may arise if extra rules based on nonlinear calculations is performed to tune FLC. The approach is based on combining two control signals, one from a conventional stabilizer, e.g. PI controller, lead lag compensator, or PSS and the other from a fuzzy logic controller. The stabilizer is designed based on modal techniques for the worst case of oscillations and is independent on the system disturbance. On the other side, the ranges of membership functions required for the design of fuzzy logic controller are selected based on the worst experience of the input/output behavior. The proposed approach is implemented on the well known Concordia model of a single machine power system to damp speed oscillations following any disturbance. Results showed a robust controller against wide range of disturbances and for parameters change which may exceed $500 \%$ of those nominal values.

\section{Appendix}

\section{Nomenclature \& System Data}

$M=$ Machine inertia coefficient $=10 \mathrm{~s}$.

$D \quad=$ Machine damping coefficient $=0$.

$\omega_{b} \quad=$ System base angle frequency $=377$.

$T_{M} \quad=$ Machine mechanical torque

$T_{E}=$ Machine electrical torque

$\omega=$ Machine speed

$\delta=$ Angle between machine quadrature axis and infinite bus

$T^{\prime}{ }_{d o}=$ direct axis transient open circuit constant $=6.0 \mathrm{~s}$.

$E_{f a}=$ Generator field voltage

$e_{t \text { Ref. }}=$ Terminal reference voltage

$e_{\text {PSS }}=$ PSS output voltage signal

$e_{i}=$ Voltage error signal

$E^{\prime}{ }_{q}=q$-axis component of voltage behind transient reactance

$K_{a}=$ Exciter amplifier gain $=25.0$

$T a=$ Exciter amplifier time constant $=0.05 \mathrm{~s}$.

$X d=d$-axis reactance $=1.6$ p.u.

$X q=q$-axis reactance $=1.55$ p.u.

$X^{\prime} d=d$-axis transient reactance $=0.32 p . u$.

$P \quad=$ Machine active power loading $=1 . p . u$.

$Q \quad=$ Machine reactive power loading $=0.2$ p.u.

$X e=$ transmission line reactance $=0.4$ p.u.

Prefix 4 stands for small change 


\section{References}

[1] Mamdani, E.H. and S.Assilian, " An experiment in liguistic synthesis with a Fuzzy Logic Controller." International Journal of Man-Machine Studies, Vol.7, No. 1, pp. 1-13, 1975.

[2] Hassan, M.A.M., Malik, O.P. and Hope, G.S., " A Fuzzy Logic Based Self-Tuned Power System Stabilizer" IEE, Third International Conference On Power System Monitoring and Control.pp.146-151, London U.K. June 1991.

[3] Hassan, M.A.M., Malik, O.P. and Hope, G.S., " A Fuzzy Logic Based Stabilizer for a Synchronous Machine" IEEE Trans.On Energy Conversion, Vol.6, No.3, pp.407-413. Sept. 1991.

[4] Hiyama, T., " Application of Rule-Based Stabilizing Controllers to Electrical Power Systems" IEE Proc. C., Vol. 136, No.3, pp. 175-181, 1989.

[5] Hiyama, T., " Rule-Based Stabilizer for Multi-Machine Power System" IEEE trans. On Power Systems, Vol.5, No.2, pp.403-411, 1990

[6] deMello, F.P. and Concordia, C. "Concepts of synchronous machine stability as affected by excitation control" IEEE Trans. Vol. PAS-87, pp.316-329, 1969.

[7] Yang, T.C., Munro, N. and Brameller, A. ," Application of optimal regulator design method through the inverse problem approach to the power system stabilizer design" Journal of Electric Power \& Energy Conversion, Vol. 13, No.1 , pp.57-62, Feb. 1991.

[8] Yang, T.C. and Munro, N., " Power system stabilizer design based on the pole assignment technique for SIMO systems." Journal of Electric Power \& Energy Conversion, Vol. 13, No.6, pp.298-302, Jan. 1992.

[9] Yang, T.C.," Synchronous generator stabilizer design through incomplete state feedback" Journal of Electric Power \& Energy Conversion, Vol. 16, No.2 , pp.91-95, Sept. 1994.

[10] Wang. L., " Damping effects of supplementary excitation control signals on stabilizing generator oscillations." Journal of Electric Power \& Energy Conversion, Vol. 18, No.1 , pp.4753, 1996.

[11] Abdel-Hamid, A.M. and H.A. Nour Eldin, "A Modal Analysis Based Load Frequency Control Considering Parameter Uncertainties And Generation Rate Constraints."

42. Internationales Wissenschaftliches Kolloquim, Band.3, pp. 705-710, Technische Universitaet Ilmenau, Germany, sept.1997.

[12] Mamdani, E.H. , " Applications of Fuzzy Logic to approximate reasoning usinglinguistic synthesis, " IEEE trans. on Computers, Vol. 26, No.12, pp. 1182-1191, 1977.

[13] Zadeh, L. A. :" Fuzzy Logic Toolbox for use with Matlab" User's Guide Version 2, Mathworks, Jan. 1998. 


\title{
عنوان البحث:
}

إتجاه جديد لتطوير آداء حاكمات المنطق المشوش الغامض (الفاظى) للنظم ذات المدى الواسع من الأخطاء والبارامترات الغير مؤكدة

\author{
د . عبدالحمبي محمد عبدالحميد

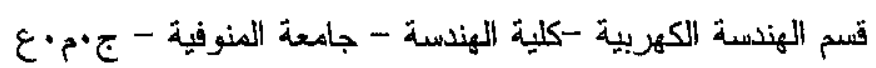

\section{ملخص البحث}

كثير آ ما يلزم إضـافـة خوارزم موائمسة عند تطبيق حاكمـات المنطفق المشوش الغـامض (الفاظى) لتدسين آدائها فى مواجهة اخطاء و إضطر ابات النظام، وتعتبر ثلك الخوارزمـات إضافة وزيادة في ثكلفة تلاك الحاكمات عـلاوة على التعقيدات الناشئة عنها خاصـة عند هر احل الثطبيق العملى · لذلاك يقدم هذا البحث طريقة مبنكرة لعمل مو ائمسة ذاتيـة للحساكم تمكنه من خمد الأبذات مهما تغيرت وتفاوتت الأخطاء والإضطر ابات التى يتعرض لها النظام بالإضافة الى أنها تحافظ على درجـة عاليـة فـى مثانة الحساكم ليسمح بـأن نكون بار امتز ات النظام المطبق عليه غير مؤكدة فى مدى يصل الى 土 . .0\% • وفكرة الطريقة الجديدة تقوم على أساس تجميع إثشارتين للتحكم واحده من أى حساكم ثقليدى يتم تصميمـه بإستخدام التحليل النسفى عند أسبوأ الظروف وبهذا نضمن عدم إعتماده علـى مسدى الإضطر ابات ،والإشارة الأخرى تؤخذ من حاكم المنطف المشوش الغـامض (الفـاظى) و الذى يصمم على أساس أسوأ الذبرات فى السلوك بين الاخـل والخرج اللنظـام · وبذلك

نضن إجتناء مميزات الحاكمان معاً . 